Article

\title{
An Entropy-Based Failure Prediction Model for the Creep and Fatigue of Metallic Materials
}

\author{
Jundong Wang ${ }^{1}$ and Yao Yao ${ }^{1,2, *}$ \\ 1 School of Mechanics, Civil Engineering and Architecture, Northwestern Polytechnical University, \\ Xi'an 710072, China; wangjundong@nwpu.edu.cn \\ 2 School of Civil Engineering, Xi'an University of Architecture and Technology, Xi'an 710055, China \\ * Correspondence: yaoy@nwpu.edu.cn
}

Received: 29 September 2019; Accepted: 29 October 2019; Published: 12 November 2019

\begin{abstract}
It is well accepted that the second law of thermodynamics describes an irreversible process, which can be reflected by the entropy increase. Irreversible creep and fatigue damage can also be represented by a gradually increasing damage parameter. In the current study, an entropy-based failure prediction model for creep and fatigue is proposed based on the Boltzmann probabilistic entropy theory and continuum damage mechanics. A new method to determine the entropy increment rate for creep and fatigue processes is proposed. The relationship between entropy increase rate during creep process and normalized creep failure time is developed and compared with the experimental results. An empirical formula is proposed to describe the evolution law of entropy increase rate and normalized creep time. An entropy-based model is developed to predict the change of creep strain during the damage process. Experimental results of metals and alloys with different stresses and at different temperatures are adopted to verify the proposed model. It shows that the theoretical predictions agree well with experimental data.
\end{abstract}

Keywords: entropy increase rate; creep strain; damage mechanics; fatigue; metallic material

\section{Introduction}

In the past decades, fatigue of materials has been investigated extensively with respect to crack nucleation, propagation, and life prediction under cyclic loading. Numerous theoretical models have been proposed based on statistics or empirical methods. The models adopted in industry are usually empirical and the physical mechanism of fatigue damage and life prediction still requires further study.

Creep is time-dependent and can be accelerated by increasing of the stress and temperature. It is one of the common damage modes in engineering such as turbine blades, thermal plants, and thermonuclear installations, especially at high-temperature conditions. The creep deformation can emerge even when the applied stress is below the elastic limit, which is more pronounced when the ambient temperature approaching the melting point of materials. Generally, the creep deformation behavior is distinguished by three stages: The creep strain rate decreases constantly in the first stage; the creep strain rate keeps almost constant in the second stage; and in the third stage, the creep rate increases rapidly until failure. The potential physical mechanism of different stages can be explained by the dislocation theory for metallic materials [1-6]. The dislocation density changes during the creep process, micro-voids nucleate in the first stage, and the coalescence and propagation mechanism of micro-voids occur in the second and the third stages simultaneously, which leads to the final fracture.

The relationship between creep strain rate and creep life was widely investigated theoretically and experimentally for different engineering materials. Monkman and Grant [7] proposed a model to describe the evolution law of steady creep strain rate and creep life and it was successfully applied to metallic materials. This model was subsequently modified by considering the damage parameters to 
describe the creep behavior [8-11]. Dyson and Gibbons [12] related the normalized creep strain and time by considering the applied stress and damage variable during the creep process. The proposed model linked the strain with time by introducing a damage variable. One of the widely adopted creep life prediction models for carbon steel is proposed by Fields [13]. A power law is applied to relate the creep stress and time. The parameters in this model can be determined from experiments [14].

The applications of thermodynamic methodology to contact problems [15-17] introduced entropy into solid mechanics. The specific entropy was applied for the complex systems under mechanical fatigue, thermal loading, friction, and wear conditions [18-20]. The entropy increase rate was studied under the framework of Boltzmann probabilistic theory and continuum damage mechanics [21]. A low-cycle fatigue life prediction model was proposed with respect to the entropy increase rate [21]. Based on the second law of thermodynamics, creep damage process is also irreversible, which can be represented by the increasing of entropy in the entire creep life.

In the current study, the entropy increase rate model and its application in fatigue life prediction is reviewed. Then, the entropy increase rate model is applied to describe the creep behavior. The relationship between entropy increase rate and normalized creep time is investigated based on the experimental analysis. A unified entropy increase trend was observed for metallic materials under different experimental conditions. An empirical formula is then proposed to describe the entropy increase rate during creep process. An entropy-based creep life prediction model is obtained by solving an ordinary differential equation. Comparison with experimental data indicates that the proposed model can accurately predict creep behavior of metallic materials with different stresses and temperatures.

\section{The Change Regulation of Entropy Increase Rate during Degeneration Process}

For ideal gas system, Boltzmann [22] defined a precise relationship between the disorder state and entropy:

$$
S=k_{0} \ln (W)
$$

where $k_{0}$ is the Boltzmann constant and $W$ is the disorder state parameter, which represents the probability of the system to exist in the current state relative to all the possible states. Although it is difficult to determine the value of $W$, Equation (1) provides an approach to determine the disorder of molecular thermal motion in the system.

The relation between entropy per unit mass and the disorder parameter was improved by Basaran et al. [20]. The disorder state parameter $W$ was defined as a function of the entropy $S$, Avogadro constant, and the specific mass $m_{s}: W=\exp \left(S m_{s} / N_{0}\right)$. Basaran et al. [23-27] proposed a relation between the entropy per unit mass and disorder state parameter; a damage law is then developed, which links the damage parameter $\mathrm{D}$ and entropy $\mathrm{S}$ :

$$
D=D_{c r} \frac{W-W_{0}}{W}=D_{c r}\left[1-\exp \left(-\frac{m_{\mathcal{S}}\left(S-S_{0}\right)}{N_{0} k_{0}}\right)\right]
$$

where $W_{0}$ represents the disorder corresponding to the initial state of the continuous medium with entropy $S_{0}$ and $D_{c r}$ is the critical value of damage approaching final failure.

The degeneration process, such as creep and fatigue, is not only a damage process, but also irreversible, which is consistent with the second law of thermodynamics. Although the damage variable is an artificially defined quantity in the viewpoint of solid mechanics, it has the same trend for entropy without decreasing. Determination of damage parameters requires different physical quantities including the elasticity modulus, micro-hardness, density, and electrical resistance etc. Variation of these physical quantities represents the corresponding microstructure change of material. The variation of entropy during the damage process represents the logarithm change of the molecular configurations [22]. Both quantities represent the microstructure change in different states, one for an outward manifestation and the other for the essential molecular configurations. In addition, the entropy 
and damage parameters are all monotonically changed during the degeneration process. Hence, it is possible to establish a connection between the damage variable and entropy.

A classical damage rate model was proposed by Bonora [28] based on the continuous damage mechanics and the plastic part of the Ranberg-Osgood power law:

$$
\dot{D}=-\dot{\lambda} \frac{\partial \Phi}{\partial Y}=\frac{K^{2}}{2 E a_{0}} \frac{\left(D_{c r}-D\right)^{\frac{\alpha-1}{\alpha}}}{p} f\left(\frac{\sigma_{m}}{\sigma_{e q}}\right) \frac{\dot{\lambda}}{1-D}
$$

where $K$ and $a_{0}$ are the material constants, $\dot{\lambda}$ is plastic multiplier, $\alpha$ is the damage exponent and can be obtained by determining the change of elastic modulus during the damage process, $f\left(\frac{\sigma_{m}}{\sigma_{e q}}\right)$ is a factor, and for uniaxial loading $f\left(\frac{\sigma_{m}}{\sigma_{e q}}\right)=1$. By applying the relation between plastic multiplier $\dot{\lambda}$ and cumulative plastic strain rate $\dot{p}: \dot{\lambda}=\dot{p} \cdot(1-D)$, Equation (3) can be written in another form:

$$
\dot{D}=\frac{K^{2}}{2 E a_{0}} \frac{\left(D_{c r}-D\right)^{\frac{\alpha-1}{\alpha}}}{p} f\left(\frac{\sigma_{m}}{\sigma_{e q}}\right) \frac{\dot{p}}{p}
$$

The damage variable $D$ has two threshold values, $D_{0}$ and $D_{c r}$. The threshold $D_{0}$ represents the initial value of damage variable presented in material microstructure or the value at the beginning of creep or fatigue damage accumulation. The threshold $D_{c r}$ is the critical value of damage variable when creep or fatigue failure occurs. The corresponding cumulative plastic strain for $D=D_{0}$ and $D=D_{c r}$ are $p_{t h}$ and $p_{c r}$, respectively. Integrating Equation (4) between $\left[D, D_{c r}\right]$ and $\left[p, p_{c r}\right]$ gives:

$$
\left(D-D_{c r}\right)^{1 / \alpha}=\frac{K^{2}}{2 E a_{0} \alpha} \ln \left(\frac{p_{c r}}{p}\right) f\left(\frac{\sigma_{m}}{\sigma_{e q}}\right) .
$$

Based on the plasticity damage dissipation potentials in Equation (2), an entropy increasing rate model for uniaxial state was proposed (detailed derivation can be found in [21]):

$$
\dot{S}=\frac{N_{0} k_{0} \alpha}{m_{S} \ln \left(p_{c r} / p\right) f\left(\sigma_{m} / \sigma_{e q}\right)}\left[\dot{f}\left(\frac{\sigma_{m}}{\sigma_{e q}}\right) \ln \left(\frac{p_{c r}}{p}\right)-f\left(\frac{\sigma_{m}}{\sigma_{e q}}\right) \frac{\dot{p}}{p}\right]
$$

For the uniaxial loading case, Equation (6) can be written as:

$$
\dot{S}=\frac{N_{0} k_{0} \alpha}{m_{S} \ln \left(p_{c r} / p\right)} \cdot \frac{\dot{p}}{p}
$$

Equation (7) describes the entropy increase rate for general mechanical process and the proposed model was successfully applied to the low-cycle fatigue life prediction of metallic materials [21]:

$$
\frac{N_{i n}}{N_{f}}=-\frac{N_{0} k_{0} \alpha}{s_{c r} m_{s}}\left[\ln \left(\ln \left(\frac{p_{c r}}{p}\right)\right)-\ln \left(\ln \left(\frac{p_{c r}}{p_{t h}}\right)\right)\right]
$$

All the parameters in Equation (8) have clear physical meaning, where $N_{0}$ and $k_{0}$ are physical constants; $\alpha, m_{s}, s_{c r}, p_{t h}$, and $p_{c r}$ are parameters related to the material properties and can be obtained from experiments. It should be note that Equation (8) can also be applied in the accelerated fatigue test; the fatigue life can be obtained by the same initial cycles of fatigue with a well-determined database.

\section{The Relation of Entropy Increase Rate and Normalized Creep Time}

As the creep process is also an irreversible degradation process, Equation (7) can be applied in the creep process. 
To investigate the increase rate of entropy in the creep process, a wide variety of creep experimental data for metals and alloys from literature were adopted [29-38]. Detailed experimental data sources are listed in Table 1 and summarized as follows: Creep tests for $9 \mathrm{Cr}-1 \mathrm{Mo}$ steel were performed at different temperatures $\left(500^{\circ} \mathrm{C}, 550^{\circ} \mathrm{C}, 600^{\circ} \mathrm{C}\right.$, and $650{ }^{\circ} \mathrm{C}$ ) under various stress levels from $80 \mathrm{MPa}$ to $320 \mathrm{Mpa}$ by using a uniaxial-load creep test frame $[29,30]$. Creep tests for $9 \mathrm{Cr}-3 \mathrm{~W}-3 \mathrm{Co}-1 \mathrm{CuVNbB}$ were performed at different temperatures $\left(625^{\circ} \mathrm{C}, 650^{\circ} \mathrm{C}\right.$, and $\left.675^{\circ} \mathrm{C}\right)$ and stress levels $(120-220 \mathrm{MPa})$ by using creep machines (RDJ 50 CRIMS) [31]. Creep tests for aluminum alloys [32,33] were adopted to verify the proposed model. Creep tests for Bar 257 were performed at $650{ }^{\circ} \mathrm{C}$ with a stress range from $70 \mathrm{MPa}$ to $100 \mathrm{MPa}$ [34]. Creep tests of Ni-base superalloy were performed at different directions and heat treatments [35]. Creep tests of Q460 steel were carried out at nine temperatures in the range of $300-900{ }^{\circ} \mathrm{C}$ and at various stress levels ranging from $13 \mathrm{MPa}$ to $509 \mathrm{MPa}$ [36]. Constant load creep tests of $\mathrm{Co}-\mathrm{Cr}-\mathrm{Mo}$ alloy were conducted at a temperature range of $650-800{ }^{\circ} \mathrm{C}$ and a stress range of 240-330 MPa [37]. The creep samples of DZ125 were machined such that the applied stress is along the [001] orientation [38]. The creep entropy increase rate was determined by Equation (7). The cumulative plastic strain rate was obtained by taking the slope of figures, which contains two coordinate axes: Creep strain and creep time. Other parameters were determined in the previous research [21]. The negative entropy increase rate $(-\mathrm{dS} / \mathrm{dt})$ with normalized creep time $(\mathrm{t} / \mathrm{tf})$ for materials at different temperatures and applied creep stresses are shown in Figure 1.

Table 1. The experimental data adopted in the current study.

\begin{tabular}{cc}
\hline Materials & Experimental Data Sources \\
\hline 9 Cr-1Mo steel & {$[29,30]$} \\
9 Cr-3W-3Co-1CuVNbB martensite ferritic steel & {$[31]$} \\
Aluminium alloy at $150{ }^{\circ} \mathrm{C}$ & {$[32]$} \\
$\mathrm{Al} 2024-\mathrm{T} 3$ & {$[33]$} \\
$\mathrm{Al} 2124$ & {$[33]$} \\
Bar 257 steel at $650{ }^{\circ} \mathrm{C}$ & {$[34]$} \\
Ni-base superalloy & {$[35]$} \\
Q460 steel & {$[36]$} \\
Co-Cr-Mo alloy & {$[37]$} \\
DZ125 super alloy & {$[38]$} \\
\hline
\end{tabular}

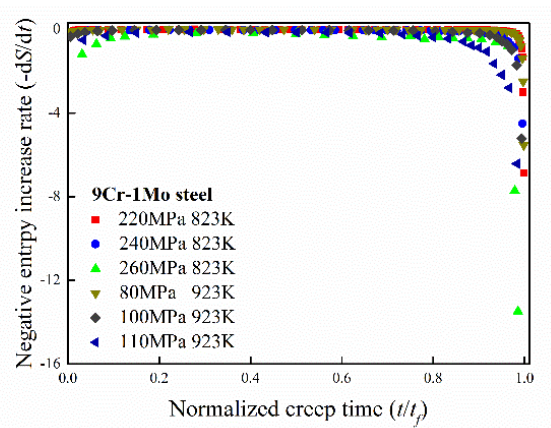

(a)

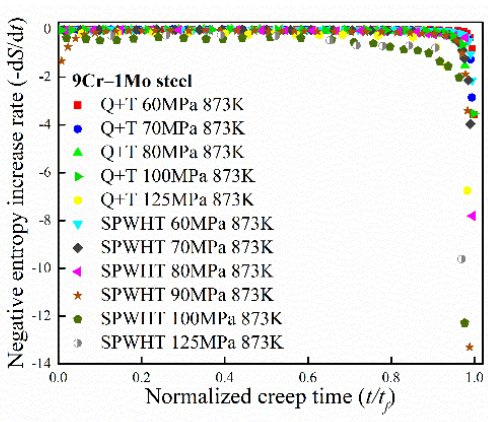

(b)

Figure 1. Cont. 


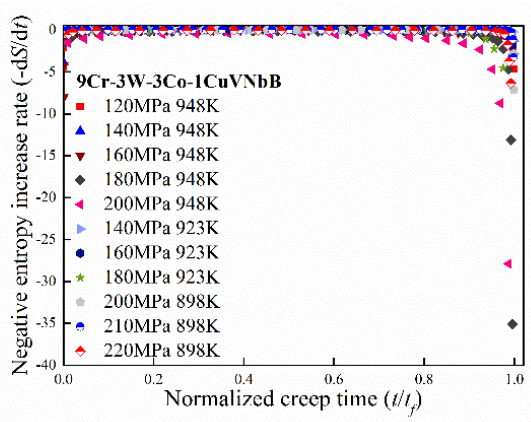

(c)

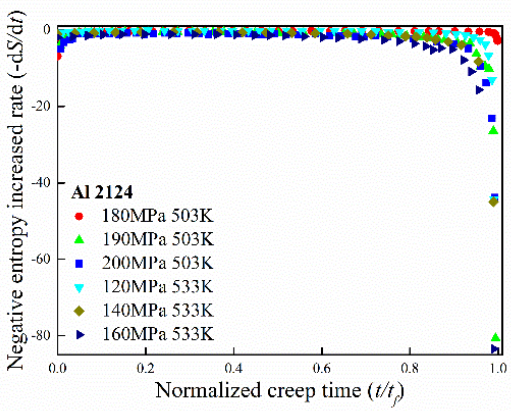

(e)

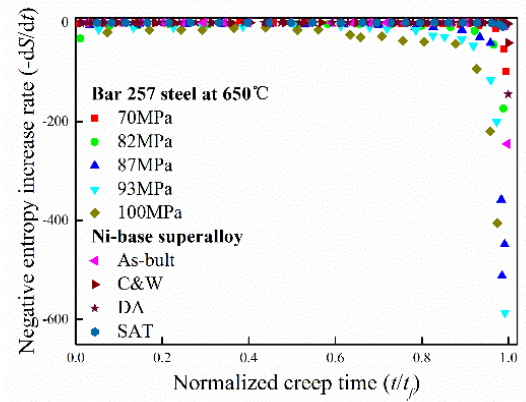

(g)

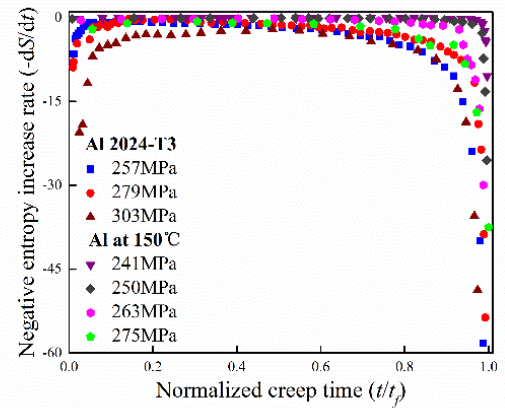

(d)

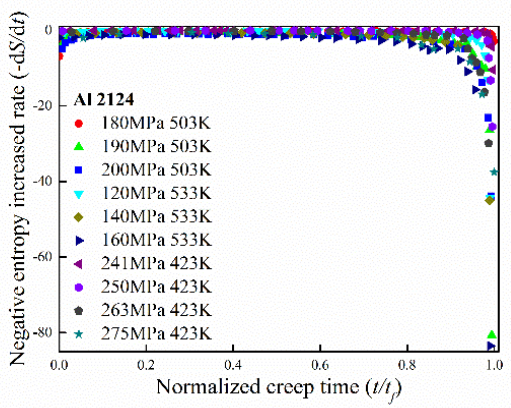

(f)

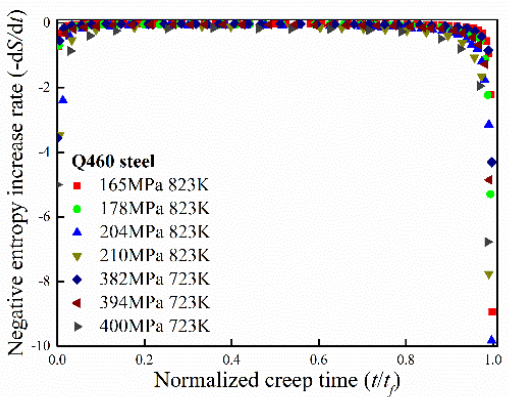

(h)

Figure 1. Change of the entropy increase rate with normalized creep time in the whole creep process: (a) 9Cr-1Mo steel at different temperatures; (b) 9Cr-1Mo steel under different treatment conditions (Q + T and SPWHT); (c) 9Cr-3W-3Co-1CuVNbB steel at different temperatures; (d-f) aluminum alloy at different temperatures; (g) Bar 257 steel and Ni-base super alloy at different temperatures; (h) Q460 steel at different temperatures.

As shown in Figure 1, the variation trend of entropy increase rate in creep process remains almost identical for different materials. In the early stage of creep, the dislocation multiplication and continuous movement lead to hardening of material. The entropy increasing rate decreases rapidly with time and then reaches a balance state. In the second stage, the creep strain rate achieves the minimum value and the entropy of the system increases at a fixed rate. In the last stage, the creep strain rate increases rapidly until the final fracture. The massive point defect separates out quickly at the grain boundary. The vacancy defect accelerates the creep strain rate and the final fracture. The entropy increasing rate of the system also increases rapidly in the last creep stage, which corresponds to increasing of the disorder degree of microstructure; the entropy increase rate attains infinity large when the final fracture occurs.

It should be noted that the entropy increase rate always keeps positive although its value reduces first and then increases; this phenomenon is consistent with the second law of thermodynamics. 
Comparison with experimental data shows that degeneration process during creep can be well represented by Equation (7).

To describe the variation trend of entropy increase rate with normalized creep time, an empirical formula is proposed based on the boundary features and the characteristics of Figure 1:

$$
\dot{S}=A \cdot \frac{1}{t} \cdot \frac{1}{\ln \left(t / t_{f}\right)}
$$

where $A$ is a parameter related to the constant creep stress, environment temperature, and material properties; $t_{f}$ is the time when final creep fracture occurs. The curve shape of Equation (9) shows sufficient similarity to ensure the characterization of entropy increase rate by continuous functions.

Experimental data for different metallic materials have been adopted to verify Equation (9). For simplification, six group of experimental data for different material are shown in Figure 2. In general, the theoretical predictions agree well with the experimental data.

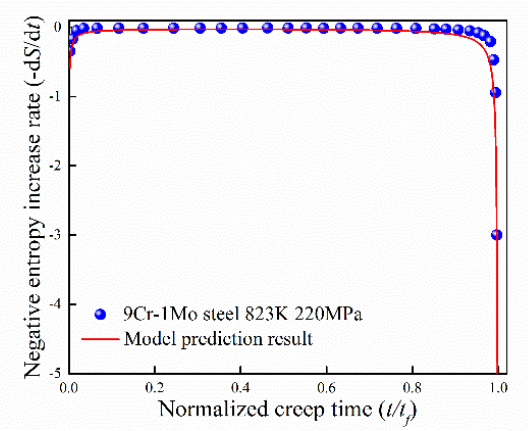

(a)

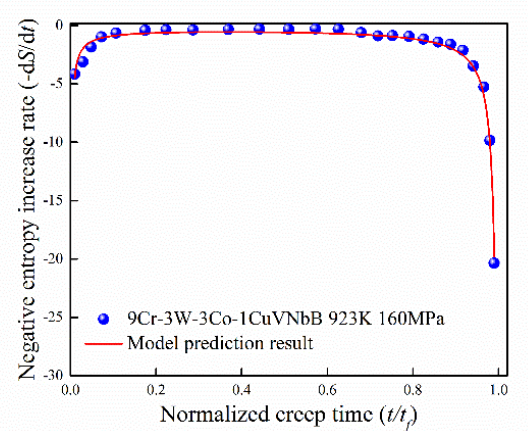

(c)

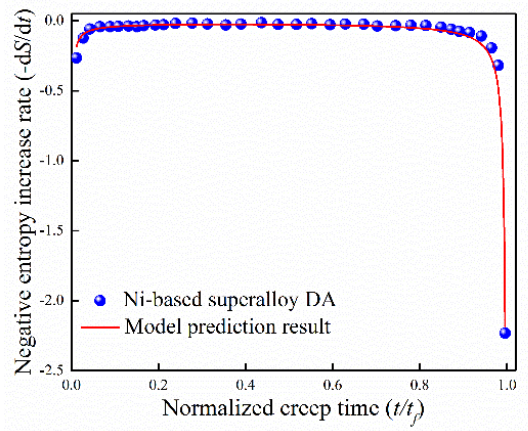

(e)

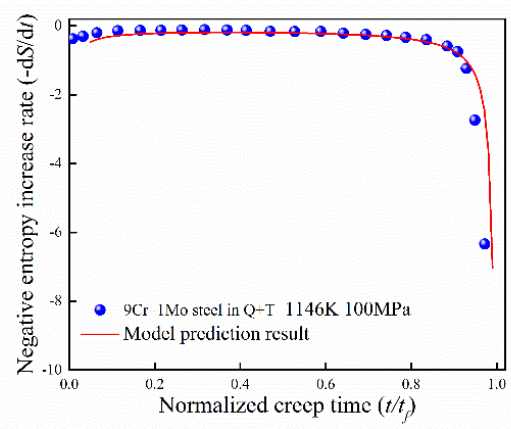

(b)

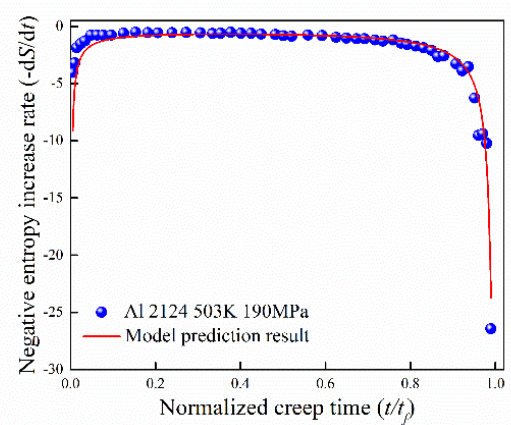

(d)

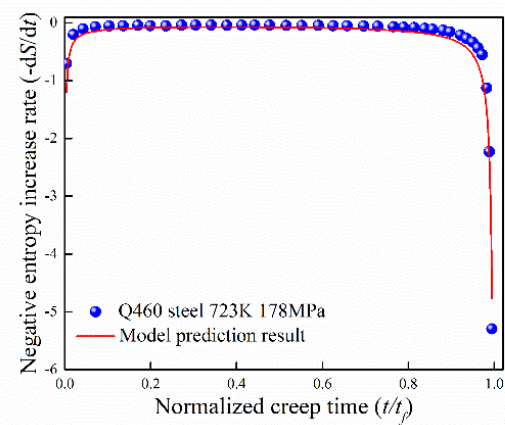

(f)

Figure 2. Verification of the proposed model compared with experimental data: (a) 9Cr-1Mo steel at $823 \mathrm{~K}$ with creep stress = $220 \mathrm{MPa}$ [26]; (b) 9Cr-1Mo steel in quenched and tempered $(\mathrm{Q}+\mathrm{T})$ at $1146 \mathrm{~K}$ with creep stress = $100 \mathrm{MPa}$ [27]; (c) $9 \mathrm{Cr}-3 \mathrm{~W}-3 \mathrm{Co}-1 \mathrm{CuVNbB}$ at $923 \mathrm{~K}$ with creep stress = $160 \mathrm{MPa}$ [28]; (d) $\mathrm{Al} 2124$ at $503 \mathrm{~K}$ with creep stress = $190 \mathrm{MPa}$ [30]; (e) Ni-based super alloy direct aging treatment at $718^{\circ} \mathrm{C} / 8 \mathrm{~h} / \mathrm{FC}+621^{\circ} \mathrm{C} / 10 \mathrm{~h} / \mathrm{AC}$ [32]; (f) Q460 at $723 \mathrm{~K}$ with creep stress = $178 \mathrm{MPa}$ [33]. 
As shown in Figure 2, the entropy increase rate can be well described by Equation (9). The slight fluctuation of some experimental data points in the stable creep stage may originate from the deviation of data recording form reference. Entropy approaches infinity when the final fracture occurs, thus the change of entropy increase rate in the first creep stage is smaller than that of the third stage. While in the first stage, the entropy is limited although the entropy increase rate is discontinuous at the moment of applying stress. In the stable creep stage, the entropy increase rate approaches zero and this phenomenon is consistent for different experimental conditions. Thus, the increasing of entropy during creep process is related to the change of dislocation, which corresponds to the microstructure changes in the thermodynamic level.

\section{The Entropy-Based Creep Strain Prediction Model}

The change regulation of entropy increase rate during creep process is investigated. From Equations (7) and (9), an entropy-based creep strain rate prediction equation can be obtained:

$$
\dot{p}=\frac{A m_{s} p}{N_{0} k_{0} \alpha} \cdot \frac{1}{\operatorname{tln}\left(t / t_{f}\right)}
$$

Equation (10) can be regarded as an ordinary differential equation. After adjustment of Equation (10) and integral on both sides, the creep strain can be obtained:

$$
\begin{gathered}
p=p_{c r} / \exp \left(\exp \left(\ln \left(\ln \left(\frac{p_{c r}}{p_{t h}}\right)\right)-B\left[\ln \left(\ln \left(\frac{t_{f}}{t}\right)\right)-\ln \left(\ln \left(\frac{t_{f}}{t_{t h}}\right)\right)\right]\right)\right) \\
B=\frac{A m_{s}}{N_{0} k_{0} \alpha}
\end{gathered}
$$

where $p_{t h}$ is the initial value of cumulative plasticity in the microstructure of material, which represents the value at the beginning of creep damage accumulation; $p_{c r}$ is the threshold value of cumulative plastic variable when creep failure occurs. The corresponding creep time when $p=p_{\text {th }}$ and $p=p_{c r}$ are $t_{t h}$ and $t_{f}$, respectively. The parameter $B$ is related to the applied stress, temperature, and material properties. Equation (11) can be used to predict the creep strain during the creep damage process.

To verify the developed model, experimental data for different metals and alloys were adopt for comparison. The main parameter in Equation (11) is B, which is related to the applied stress, temperature, and material properties such as elastic modulus. It can be obtained by fitting the experimental data through Equation (11). The threshold value of cumulative plastic strain and threshold time can be obtained from experiments. The initial value of cumulative plastic strain and creep time is determined by taking the first group of experimental data point and make the iterative operations. The predictions of the developed model are compared with experimental data for different materials in the following sections.

\subsection{Ni-Base Super Alloy}

The creep properties of Ni-base super alloy at different build directions and heat treatments were studied experimentally by Kuo et al. [35]. Comparison of theoretical prediction with experimental data is shown in Figure 3. In general, the predictions agree well with experimental results. The applied stress $(550 \mathrm{MPa})$ and temperature $(923 \mathrm{~K})$ remain unchanged for different test conditions. The main difference comes from the microstructure, which is reflected by different values of $\mathrm{B}$ in the developed model. However, it is difficult to effectively quantify microstructure for Ni-base super alloy at different build directions and heat treatments and establish the relation between $B$ and microstructure. 


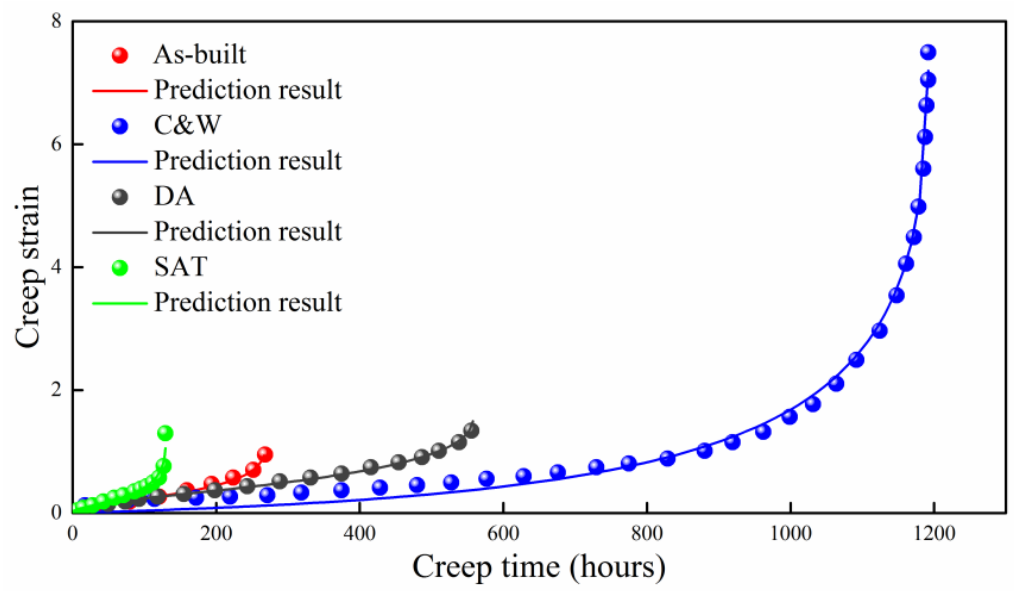

Figure 3. Prediction of Ni-base super alloy at different build directions and heat treatments. C\&W: Cast-and-wrought; STA: Solution treatment and aging treatment; DA: Direct-aging treatment.

\subsection{Q460 Steel}

The creep property of high-strength Q460 steel at different temperatures was studied by Wang et al. [36]. Decreasing of the maximum creep strain with the stress level was considered because sufficient plasticity can be developed with longer duration [36]. The maximum creep strain shows no obvious relation with creep stress for most of the cases. As shown in Figure 4, the prediction results agree well with the experimental data for both $723 \mathrm{~K}$ and $823 \mathrm{~K}$ cases. The absolute value of $\mathrm{B}$ is obtained by fitting the experimental data, which increases with the applied stress. The detailed discussion of $B$ is given in the next section.

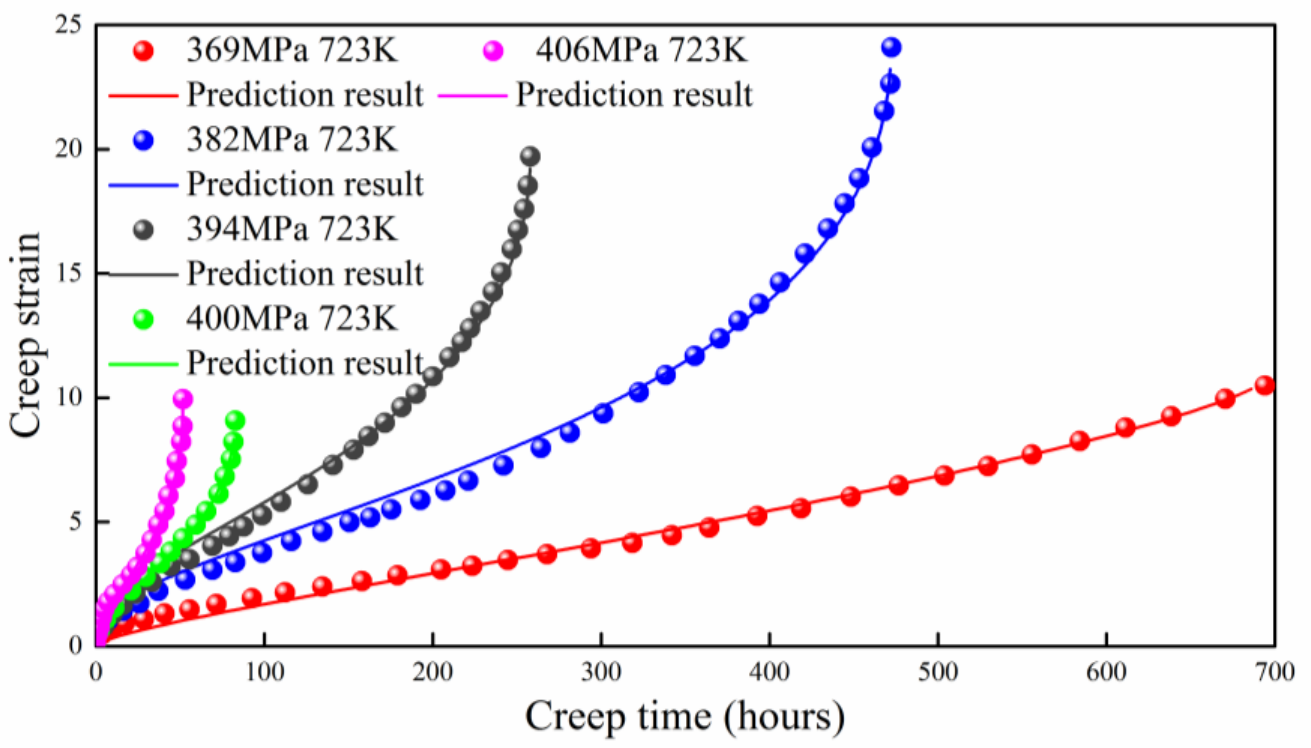

(a)

Figure 4. Cont. 


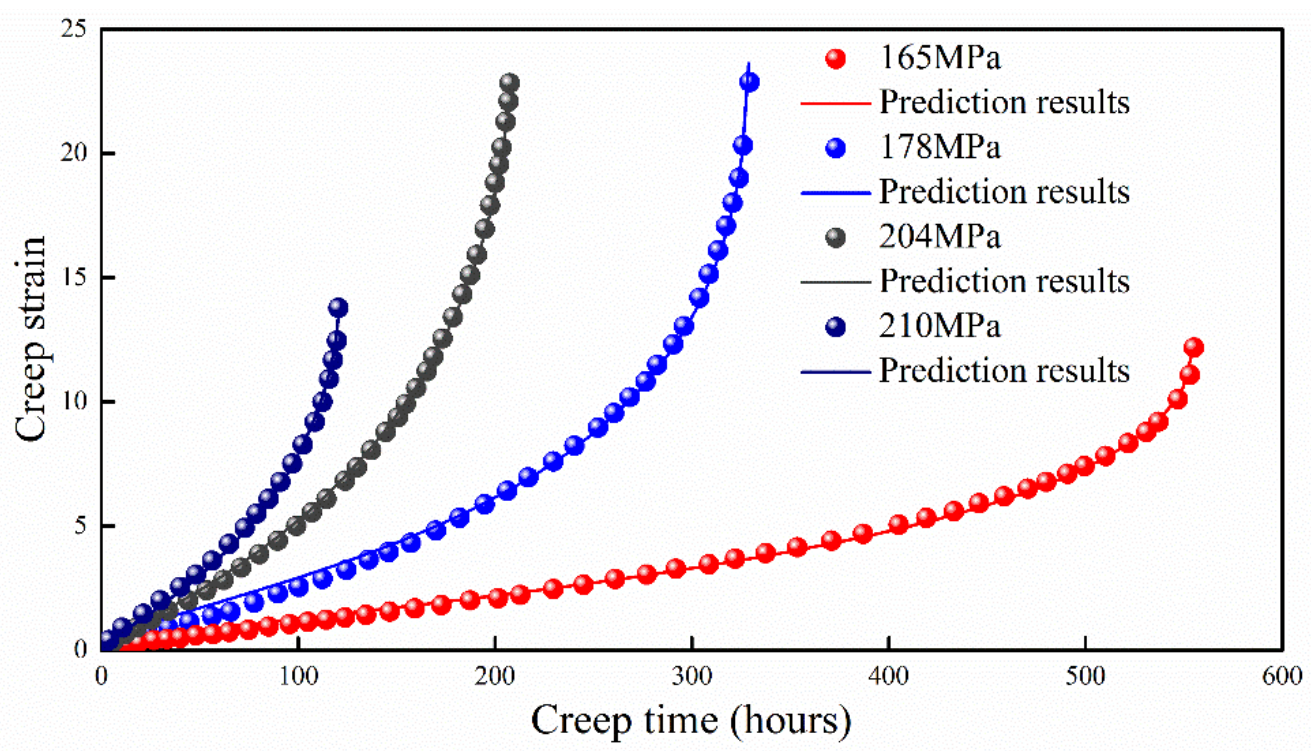

(b)

Figure 4. Prediction result of high strength Q460 steel at different temperatures; (a) $723 \mathrm{~K}$; (b) $823 \mathrm{~K}$.

\subsection{Bar 257 Steel at $923 \mathrm{~K}$}

As shown in Figure 5, the predictions of proposed model agree well with the experimental data for Bar 257 steel at $923 \mathrm{~K}$ [34], except for the applied stress of $70 \mathrm{MPa}$. The predicted creep strain is slight larger around the final fracture region. The absolute value of $\mathrm{B}$ also increases with the applied stress. The prediction with an applied stress of $87 \mathrm{MPa}$ does not cover the last two data points as the prediction is composed of 1000 data points; this problem can be solved by making the data points denser (for instance, 3000 data points).

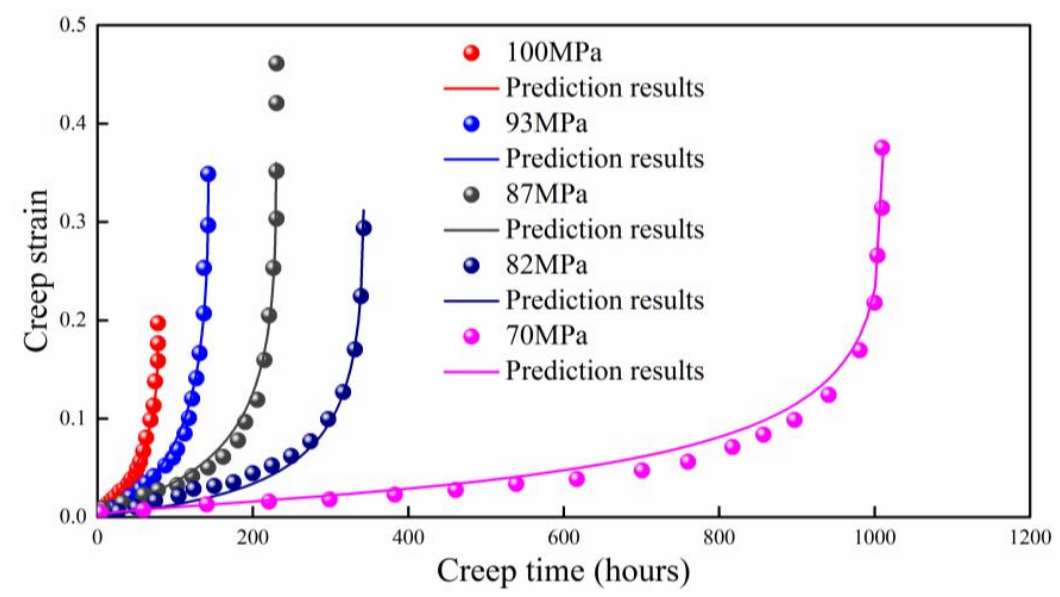

Figure 5. Prediction result of Bar 257 steel at $923 \mathrm{~K}$.

\subsection{Al 2124 at $503 \mathrm{~K}$ and $533 \mathrm{~K}$}

The high-temperature creep behaviors of $\mathrm{Al} 2124$ at $473 \mathrm{~K}, 503 \mathrm{~K}$, and $533 \mathrm{~K}$ were studied by $\mathrm{Li}$ et al. [33]. The theoretical prediction results are shown in Figure 6. Because the discontinuity of experimental data at $473 \mathrm{~K}(235 \mathrm{MPa})$ during the creep damage process, only the experimental data of $503 \mathrm{~K}$ and $533 \mathrm{~K}$ were selected to benchmark the proposed model. It shows that the prediction results agree well with the experimental data. With increasing of the applied stress, the absolute value of $\mathrm{B}$ increases as well. 


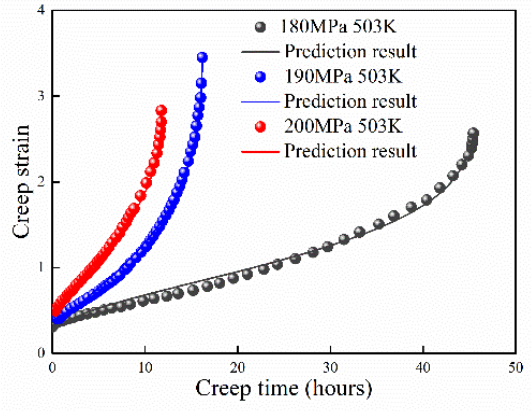

(a)

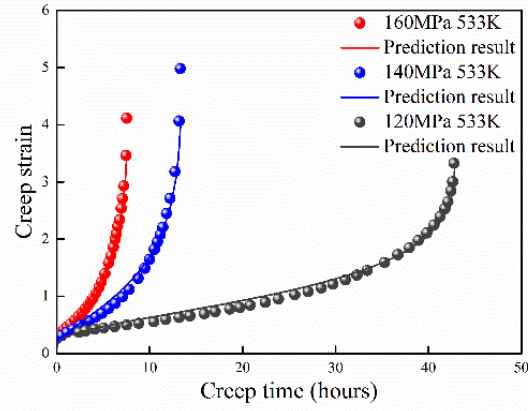

(b)

Figure 6. Prediction results of $\mathrm{Al} 2124$ at (a) $503 \mathrm{~K}$ and (b) $533 \mathrm{~K}$.

\subsection{Cr-1Mo Steel at $823 \mathrm{~K}$ and $923 \mathrm{~K}$}

The creep behavior of modified 9Cr-1Mo steel at $823 \mathrm{~K}$ and $923 \mathrm{~K}$ were studied by Zhang et al. [30]. Comparison of the experimental data and prediction results are shown in Figure 7. The maximum creep strain approaches at $923 \mathrm{~K}$ for different stresses. However, this phenomenon was not observed for most of the other metals and alloys. Thus, it is hard to take the maximum plastic strain to evaluate the creep life [30]. The creep strain was well predicted with creep time by the proposed model. The absolute value of B increases with the applied stress.

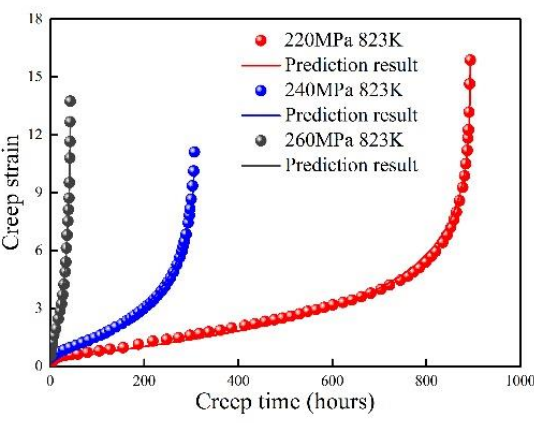

(a)

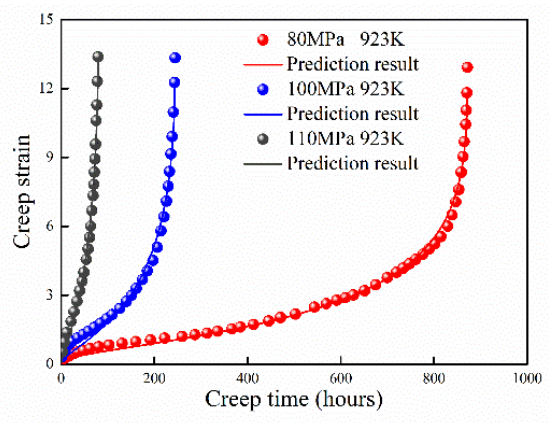

(b)

Figure 7. Prediction results of 9Cr-1Mo steel at (a) $823 \mathrm{~K}$ and (b) $923 \mathrm{~K}$.

\subsection{Cr-3W-3Co-1CuVNbB Martensite Ferritic at 898 K, $923 \mathrm{~K}$, and $948 \mathrm{~K}$}

Xiao et al. [31] systematically investigated the creep behavior of $9 \mathrm{Cr}-3 \mathrm{~W}-3 \mathrm{Co}-1 \mathrm{CuVNbB}$ martensite ferritic steel for a temperature range of $898 \mathrm{~K}$ to $948 \mathrm{~K}$ under uniaxial tensile stress from 120 to $220 \mathrm{MPa}$. As shown in Figure 8, predictions of the proposed model agree well with the experimental data. For the creep behavior of $9 \mathrm{Cr}-3 \mathrm{~W}-3 \mathrm{Co}-1 \mathrm{CuVNbB}$ steel under $898 \mathrm{~K}$, the first creep stage has a relatively longer time compared with other temperatures. It is difficult for the traditional models to predict the creep strain under these circumstances (it only maintains a certain precision in the first or third stages) [32]. The predictions of proposed model agree well with the experimental data except under the applied stress of $120 \mathrm{MPa}$ at $948 \mathrm{~K}$. Considering that the proposed model is single-parameter, the accuracy of prediction is acceptable. 


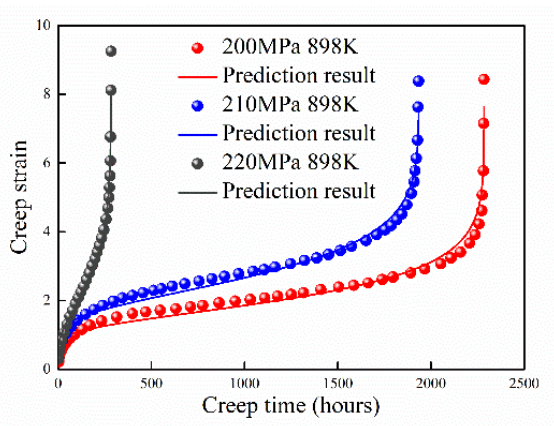

(a)

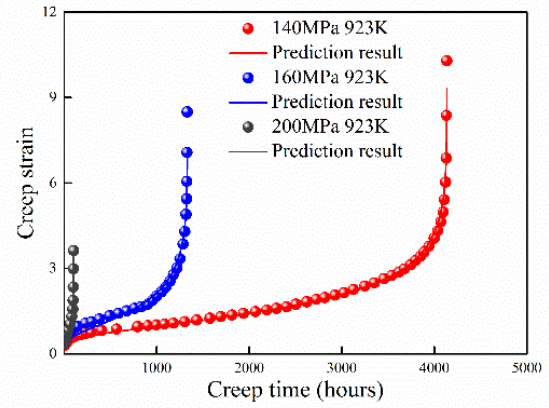

(b)

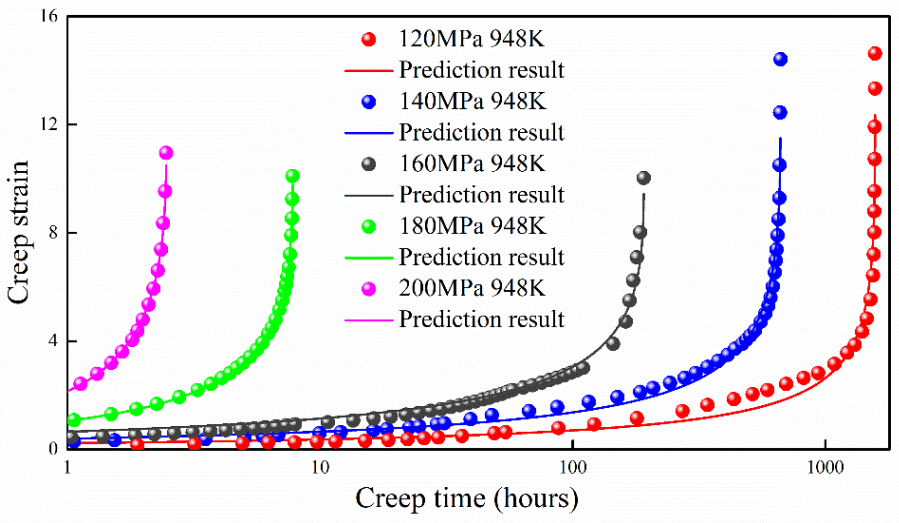

(c)

Figure 8. Prediction result of $9 \mathrm{Cr}-3 \mathrm{~W}-3 \mathrm{Co}-1 \mathrm{CuVNbB}$ martensite ferritic steel at (a) $898 \mathrm{~K}$, (b) $923 \mathrm{~K}$, and (c) $948 \mathrm{~K}$.

\subsection{Cr-1Mo Ferritic Steel in Quenched and Tempered $(Q+T)$ and Simulated Post Weld Heat Treatment (Spwht) Conditions}

The creep behavior of $9 \mathrm{Cr}-1 \mathrm{Mo}$ ferritic steel under SPWHT and $\mathrm{Q}+\mathrm{T}$ treatment was studied by Choudhary [30]. The experimental data are compared with theoretical prediction, as shown in Figure 9. The predictions of proposed model agree well with the experimental data except under $Q+T$ and SPWHT condition with the applied stress of $90 \mathrm{MPa}$. The second case is because the estimated $p_{t h}$ is not converged. The prediction is obtained by setting $p_{t h}$ as the first experimental data point. At the same time, the creep experiments usually accompanied with a certain degree of discreteness.

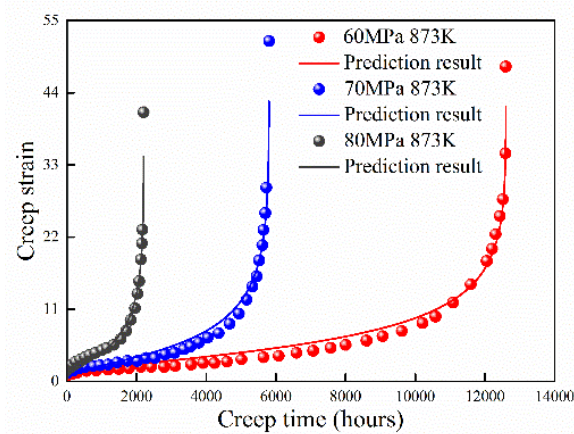

(a)

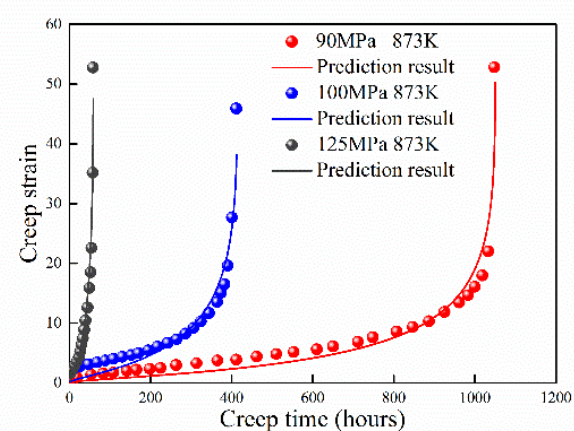

(b)

Figure 9. Cont. 


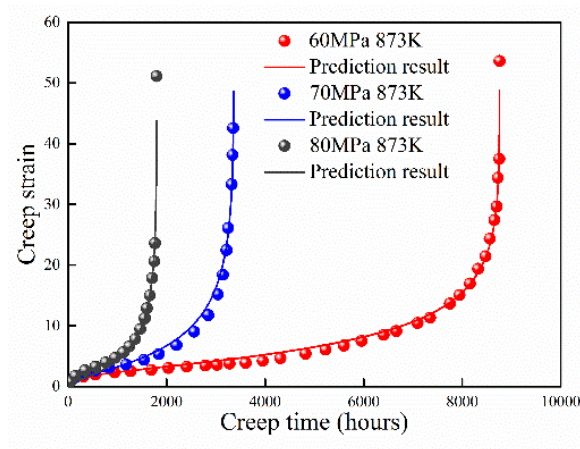

(c)

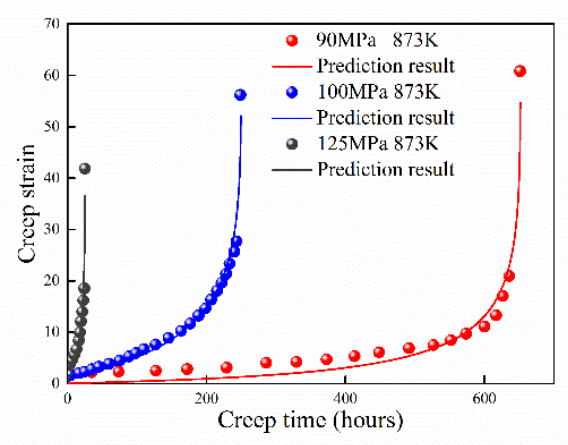

(d)

Figure 9. Prediction result of $9 \mathrm{Cr}-1 \mathrm{Mo}$ ferritic steel in quenched and tempered $(\mathrm{Q}+\mathrm{T})$ and simulated post weld heat treatment (SPWHT) conditions: (a) Q + T 60 80 MPa; (b) Q + T 90 125 MPa; (c) SPWHT 60 80 MPa; and (d) SPWHT 90 125 MPa.

\subsection{Co-Cr-Mo Alloy}

The creep behavior of Co-Cr-Mo alloy at different temperatures (923 K, $973 \mathrm{~K}, 1023 \mathrm{~K}, 1073 \mathrm{~K}$ ) was investigated by Sun et al. [37]. The experiments were carried out at a constant applied stress $(240 \mathrm{MPa})$. The theoretical prediction is compared with experimental data, as shown in Figure 10. The transverse axes is taken as logarithmic coordinates to make the difference of experimental data more obvious. Generally, the prediction results agree well with the experimental data.

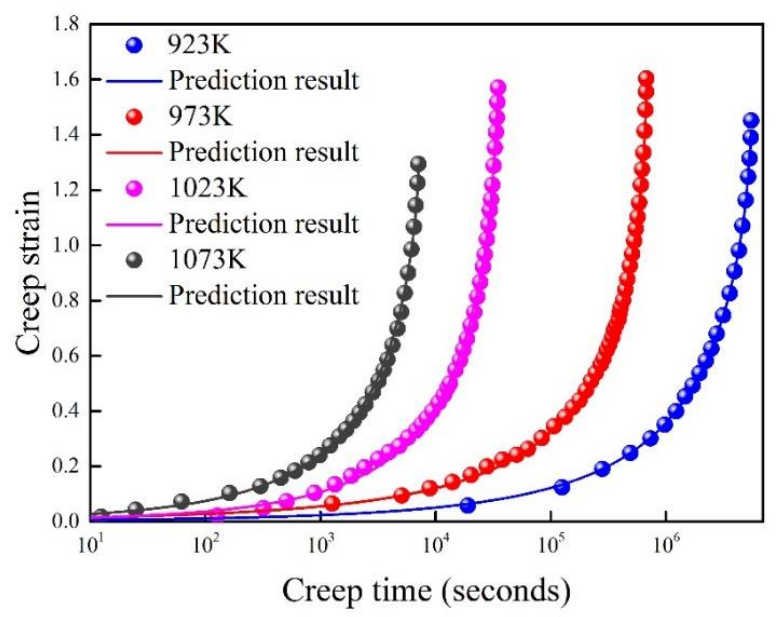

Figure 10. Prediction result of $\mathrm{Co}-\mathrm{Cr}-\mathrm{Mo}$ alloy at different ambient temperature.

\subsection{DZ125 Super Alloy}

The creep behavior of DZ125 super alloy at different creep stresses and temperatures was investigated by Fu et al. [38]. The theoretical prediction is compared with experimental data, as shown in Figure 11. The theoretical predictions agree well with the all five groups of experimental data. 


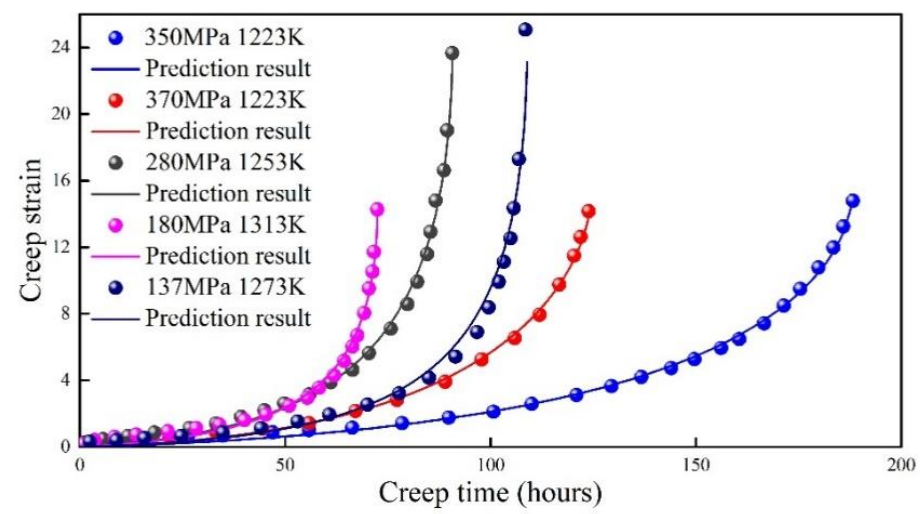

Figure 11. Prediction result of DZ125 super alloy at different creep stresses and temperatures.

\section{Parametric Analysis of the Proposed Model}

As is well known, the creep strain is strongly influenced by the applied stress and temperature. The creep strain will increase with higher applied stress and temperature. These effects cannot be ignored in the creep analysis. Therefore, the parameter B in Equation (11) should be associated with the applied stress and temperature. Assuming that these two effects are irrelevant, which is commonly accepted in the traditional models [39], the parameter B should have a form as follows:

$$
B=M \cdot f(\sigma) \cdot g(T)
$$

where $M$ is a coefficient that contains $\alpha, m_{s}, k_{0}$, and $N_{0}$. The relation between $B$ and applied stress are verified by the experimental data in Section 4 . The values of $B$ and its linear fitting with applied stress are shown in Figure 12:

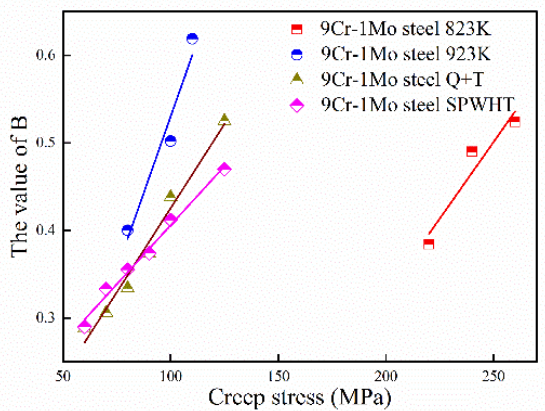

(a)

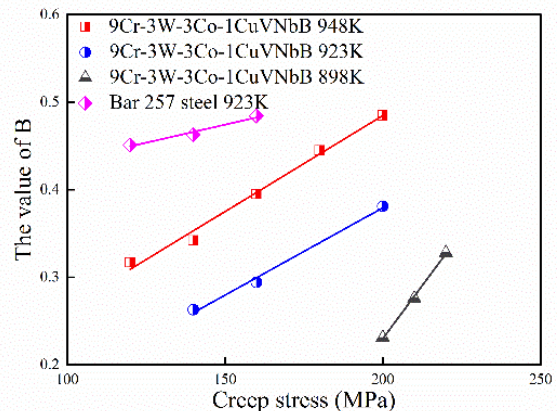

(b)

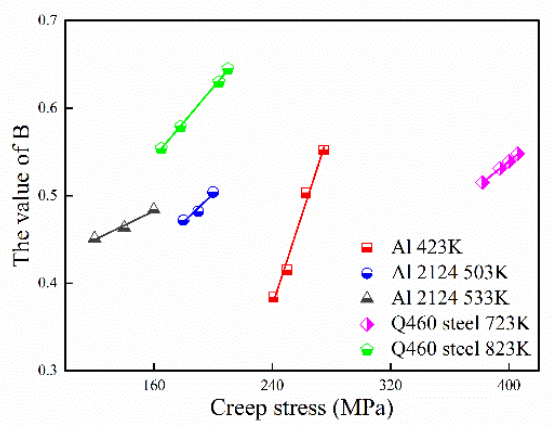

(c)

Figure 12. The relation between the parameter $B$ and applied stress. (a) $9 \mathrm{Cr}-1 \mathrm{Mo}$ steel; (b) 9Cr-3W-3Co-1CuVNbB and Bar 257 steel; (c) Al and Q460 steel. 
As shown in Figure 12, with increasing of the applied stress, the value of B also shows a near-linear increasing trend for different materials. In the current study, the value of $B$ has a relative concentration range of 0.2 0.7 (maximum $=0.645$ for Q460 steel at $210 \mathrm{MPa} 823 \mathrm{~K}$; minimum $=0.231$ for $9 \mathrm{Cr}-3 \mathrm{~W}-3 \mathrm{Co}-1 \mathrm{CuVNbB}$ at $210 \mathrm{MPa} 898 \mathrm{~K})$.

The relationship between $B$ and temperature is shown in Figure 13. With the increase in temperature, the value of $\mathrm{B}$ also increases for $9 \mathrm{Cr}-3 \mathrm{~W}-3 \mathrm{Co}-1 \mathrm{CuVNbB}$ and $\mathrm{Co}-\mathrm{Cr}-\mathrm{Mo}$ alloy. Although the relationship between $B$ and temperature approaches linear for $\mathrm{Co}-\mathrm{Cr}-\mathrm{Mo}$ alloy, determination of an accurate relationship still requires more experimental data.

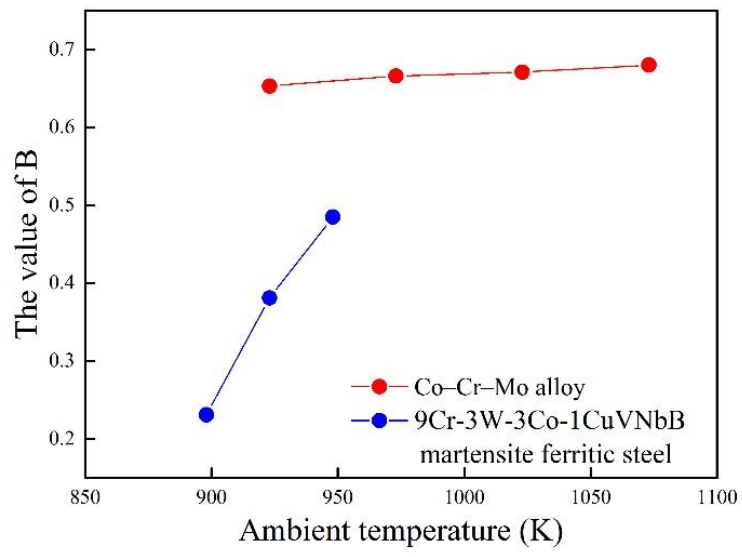

Figure 13. The relation between the parameter $B$ and temperature.

\section{Conclusions}

Based on the continuum damage mechanics and the statistical definition of entropy, the entropy increasing rate during creep process is investigated. The conclusions are summarized as follows:

1. The entropy increasing rate for creep is investigated with experimental data for different metallic materials. Similar entropy increasing trend is observed with normalized creep time. A theoretical model is proposed to describe the relationship based on the characteristic of boundary conditions. Comparison with experimental data shows that the developed model gives reasonably accurate estimation of entropy increasing rate in the creep process.

2. An entropy-based creep strain prediction model is proposed with respect to the entropy increasing rate. Predictions of the proposed model agree well with the experimental data for different metallic materials.

3. The single parameter B in the proposed model is associated with the applied stress and temperature. In general, the parameter increases linearly with the applied stress.

Author Contributions: Conceptualization, Y.Y.; supervision, Y.Y.; writing-original draft, J.W.

Funding: This research was funded by National Natural Science Foundation of China: 11572249,11772257.

Acknowledgments: The authors acknowledge the financial support by National Natural Science Foundations of China (11572249 and 11772257) and Fundamental Research Funds for the Central Universities (No. G2019KY05212).

Conflicts of Interest: The authors declare no conflict of interest.

\section{References}

1. Burke, P.M.; Sherby, O.D. Mechanical Behavior of Crystalline Solids at Elevated Temperature. Progr. Mater. Sci. 1968, 13, 323-390.

2. Brehm, H.; Daehn, G.S. A framework for modeling creep in pure metals. Metall. Mater. Trans. A 2002, 33, 363-371. [CrossRef] 
3. Kassner, M.E.; PérezPrado, M.T. Five-power-law creep in single phase metals and alloys. Progr. Mater. Sci. 2000, 45, 1-102. [CrossRef]

4. Yao, Y.; Wang, J.D.; Keer, L.M. A phase transformation based method to predict fatigue crack nucleation and propagation in metals and alloys. Acta Mater. 2017, 127, 244-251. [CrossRef]

5. Yao, Y.; Long, X.; Keer, L.M. A review of recent works on mechanical behavior of lead-free solder materials. Appl. Mech. Rev. 2017, 69, 040802. [CrossRef]

6. Yao, Y.; Fine, M.E.; Keer, L.M. An energy approach to predict fatigue crack propagation in metals and alloys. Int. J. Fract. 2007, 146, 149-158. [CrossRef]

7. Monkman, F.C.; Grant, N.J. An empirical relationship between rupture life and minimum creep rate in creep rupture tests. Proc. Am. Soc. Test. Mater. 1956, 56, 593-620.

8. Dobes, F.; Milicka, K. The relation between minimum creep rate and time to fracture. Met. Sci. 1976, 10, 382-384. [CrossRef]

9. Rabotnov, Y.N.; Leckie, F.A.; Prager, W. Creep Problems in Structural Members. J. Appl. Mech. 1970, $37,249$. [CrossRef]

10. Leckie, F.A.; Hayhurst, D.R. Constitutive equations for creep rupture. Acta Metall. 1977, 25, $1059-1070$. [CrossRef]

11. Ashby, M.F.; Dyson, B.F. Advances in Fracture Research; Pergamon Press: Oxford, UK, 1984.

12. Dyson, B.F.; Gibbons, T.B. Tertiary creep in nickel-base superalloys: Analysis of experimental data and theoretical synthesis. Acta Metall. 1987, 35, 2355-2369. [CrossRef]

13. Fields, B.A.; Fields, R.J. Elevated Temperature Deformation of Structural Steel; Report NISTIR 88-3899; NIST: Gaithersburg, MA, USA, 1989.

14. Cowan, M.; Khandelwal, K. Modeling of high temperature creep in ASTM A992 structural steels. Eng. Struct. 2004, 80, 426-434. [CrossRef]

15. Kozyrev, Y.P.; Sedakova, E.B. Application of a thermodynamic model for analysis of wear resistance of materials. J. Mach. Manuf. Reliab. 2008, 37, 60-62.

16. Bryant, M.D. Entropy and Dissipative Processes of friction and Wear. FME Trans. 2009, 37, 55-60.

17. Amiri, M.; Khonsari, M.M. On the Thermodynamics of Friction and Wear-A Review. Entropy 2010, 12, 1021-1049. [CrossRef]

18. Sosnovskiy, L.A.; Sherbakov, S.S. A Model of Mechanothermodynamic Entropy in Tribology. Entropy 2016, 19, 115. [CrossRef]

19. Sosnovskiy, L.A.; Sherbakov, S.S. Mechanothermodynamical system and its behavior. Contin. Mech. Thermodyn. 2012, 24, 239-256. [CrossRef]

20. Sosnovskiy, L.A.; Sherbakov, S.S. Mechanothermodynamics; Springer: Berlin/Heidelberg, Germany, 2016.

21. Wang, J.D.; Yao, Y. An Entropy Based Low-Cycle Fatigue Life Prediction Model for Solder Materials. Entropy 2017, 19, 503. [CrossRef]

22. Boltzmann, L. Lectures on Gas Theory; University of California Press: Berkeley, CA, USA, 1964.

23. Basaran, C.; Gomez, J.; Lin, M. Damage Mechanics Modeling of Concurrent Thermal and Vibration Loading on Electronics Packaging. Multidiscip. Model. Mater. Struct. 2013, 2, 309-326.

24. Basaran, C.; Yan, C.Y. A Thermodynamic Framework for Damage Mechanics of Solder Joints. J. Electron. Packag. 1998, 120, 379-384. [CrossRef]

25. Basaran, C.; Tang, H. Implementation of a Thermodynamic Framework for Damage Mechanics of Solder Interconnects in Microelectronic Packaging. Int. J. Damage Mech. 2002, 11, 87-108. [CrossRef]

26. Basaran, C.; Lin, M.; Ye, H. A thermodynamic model for electrical current induced damage. Int. J. Solids Struct. 2003, 40, 7315-7327. [CrossRef]

27. Basaran, C.; Nie, S. An Irreversible Thermodynamics Theory for Damage Mechanics of Solids. Int. J. Damage Mech. 2004, 13, 205-223. [CrossRef]

28. Bonora, N. A nonlinear CDM model for ductile failure. Eng. Fract. Mech. 1997, 58, 11-28. [CrossRef]

29. Shrestha, T.; Basirat, M.; Charit, I.; Potirniche, G.P.; Rink, K.K.; Sahaym, U. Creep deformation mechanisms in modified 9Cr-1Mo steel. J. Nucl. Mater. 2012, 423, 110-119. [CrossRef]

30. Choudhary, B.K. Tertiary creep behaviour of 9Cr-1Mo ferritic steel. Mater. Sci. Eng. A 2013, 585, 1-9. [CrossRef] 
31. Xiao, B.; Xu, L.; Zhao, L.; Jing, H.; Han, Y.; Zhang, Y. Creep properties, creep deformation behavior, and microstructural evolution of $9 \mathrm{Cr}-3 \mathrm{~W}-3 \mathrm{Co}-1 \mathrm{CuVNbB}$ martensite ferritic steel. Mater. Sci. Eng. A 2017, 711, 434-447. [CrossRef]

32. Li, B.; Lin, J.; Yao, X. A novel evolutionary algorithm for determining uniÿed creep damage constitutive equations. Int. J. Mech. Sci. 2002, 44, 987-1002. [CrossRef]

33. Li, L.T.; Lin, Y.C.; Zhou, H.M.; Jiang, Y.Q. Modeling the high-temperature creep behaviors of 7075 and 2124 aluminum alloys by continuum damage mechanics model. Comput. Mater. Sci. 2013, 73, 72-78. [CrossRef]

34. Hyde, T.H.; Becker, A.A.; Sun, W.; Williams, J.A. Finite-element creep damage analyses of P91 pipes. Int. J. Press. Vessel. Pip. 2006, 83, 853-863. [CrossRef]

35. Kuo, Y.L.; Horikawa, S.; Kakehi, K. Effects of build direction and heat treatment on creep properties of Ni-base superalloy built up by additive manufacturing. Scr. Mater. 2017, 129, 74-78. [CrossRef]

36. Wang, W.; Yan, S.; Liu, J. Studies on temperature induced creep in high strength Q460 steel. Mater. Struct. 2017, 50, 68. [CrossRef]

37. Sun, S.H.; Koizumi, Y.; Kurosu, S.; Lib, Y.P.; Chiba, A. Phase and grain size inhomogeneity and their influences on creep behavior of Co-Cr-Mo alloy additive manufactured by electron beam melting. Acta Mater. 2015, 86, 305-318. [CrossRef]

38. Fu, C.; Chen, Y.D.; Yuan, X.F.; Tin, S.; Antonov, S.; Yagi, K. A modified $\theta$ projection model for constant load creep curves-II Application of creep life prediction. J. Mater. Sci. Technol. 2019, 35, 687-694. [CrossRef]

39. Kraus, H.; Saunders, H. Creep Analysis. J. Mech. Des. 1982, 104, 530. [CrossRef]

(C) 2019 by the authors. Licensee MDPI, Basel, Switzerland. This article is an open access article distributed under the terms and conditions of the Creative Commons Attribution (CC BY) license (http://creativecommons.org/licenses/by/4.0/). 